\title{
TWO NEW SPECIES OF PHREATIC HARPACTICOIDS FROM IRAN (CRUSTACEA: COPEPODA)
}

\author{
by \\ GIUSEPPE L. PESCE \\ Zoological Institute of the University of L'Aquila, Italy
}

\begin{abstract}
Two new species of the genus Nitrocrella Chappuis (s. str.) are described from subterranean, phreatic waters of Iran. These two species, N. petkovski and $N$. paceae, belong according to the recent revision of Petkovski (1976) to the chappuisi and vasconica groups of the genus, respectively.

\section{RESUME}

Deux espèces nouvelles du genre Nitocrella Chappuis (s. str.) sont décrites des eaux souterraines phréatiques d'Iran. Ces deux nouvelles espèces, $N$. petkovski et $N$, paceae appartiennent, d'après la révision récente de Petkovski (1976), respectivement aux groupes chappuisi et vasconica du genre.
\end{abstract}

\section{INTRODUCTION}

In the course of recent researches on the biology of the underground phreatic waters of Iran, carried out by the Zoological Institute of the University of L'Aquila (Pesce, in press), numerous samples of interstitial harpacticoid copepods were obtained from freshwater wells in the highland of Isfahan.

Among the materials entrusted to me for study, two undescribed species of the genus Nitocrella Chappuis (s. str.) were found: these species are described and illustrated below as Nitocrella petkovskii n. sp. and Nitocrella paceae n. sp.

Many thanks are due to Professor T. K. Petkovski (Skopje) for verifying my identifications and for helpful suggestions.

\section{Nitocrella petkovskii n. sp. Fig. 1}

Materia 1. Two $q$ and three juv. (copepodids III, IV), freshwater well (IR. 34) at Shahr-e-Kord, Hafes street, Isfahan, 2,200 $\mathrm{m}$ above sea-level (water level at $4.1 \mathrm{~m}$, water depth $2.5 \mathrm{~m}$; temperature $16.2{ }^{\circ} \mathrm{C} ; \mathrm{pH} 7.5$; bottom sediment composed of small vegetable and limestone detritus); May 23, 1978; coll. Pace \& Rahim.

One $\mathcal{f}$ and one $\hat{\delta}$, freshwater well at Farrochà, Isfahan, 2,200 $\mathrm{m}$ above sea-level (water level at $30.5 \mathrm{~m}$, water depth
$5.2 \mathrm{~m}$; temperature $16.5^{\circ} \mathrm{C}$; bottom sediment composed of sandstone detritus and clay); May 24, 1978; coll. Pace \& Rahim.

In the above localities the new species lives in association with other harpacticoid copepods as Nitocrella paceae (described below) and Attheyella crassa (Sars), and with the following other organisms: Bryocyclops of. neuter Kiefer and Diacyclops bisetosus (Rehberg) (both cyclopid copepods), Candoninae (Ostracoda), Nais elinguis (Müller) (Oligochaeta), water mites, collemboles and some mosquito larvae.

Types. One $q$ (holotype) and one $\hat{\delta}$ (allotype), completely dissected and mounted in Faure's medium on microscope slides, deposited in the Zoölogisch Museum, Amsterdam; remainder (paratypes) in the Zoological Institute of the University of L'Aquila (author's collections).

Description. - Female: General shape as usual in the genus; body elongate and slender; unpigmented and blind; length well over 0.55 $\mathrm{mm}$, including furcal rami but excluding furcal setae, antennae and antennulae. Genital segment short, receptaculum seminis as in fig. 1. Antennula 8-segmented, aesthete on the 4th article much longer than the following articles together. Antenna, exopod triangular, 1-segmented and armed with 3 apical setae, the inner one plumose. Mouthparts without particular characteristics as compared to those of the other species in the genus.

$\mathrm{P}_{1}$ : endopod 3-segmented; article 1 as long as the first and second articles of the exopod together, and armed with a long inner seta which reaches the tip of the 2 nd article; article 2 without well-developed spines or setae; article 3 with 2 long apical setae and a short setula. Exopod shorter than the endopod and 3-segmented; articles 1 and 2 with 1 outer spine only, article 3 with 2 outer spines and 2 long apical setae.

$\mathrm{P}_{2}-\mathrm{P}_{4}$ : endopod 2-segmented, reaching about the middle of article 2 of the exopod; article 1 without spines or setae; article 2 with $1\left(\mathrm{P}_{2}\right.$ and $\left.\mathrm{P}_{4}\right)$ and $2\left(\mathrm{P}_{3}\right)$ long apical setae overreaching the tip of article 3 of the exopod. Exopods of $\mathrm{P}_{2}$ and 


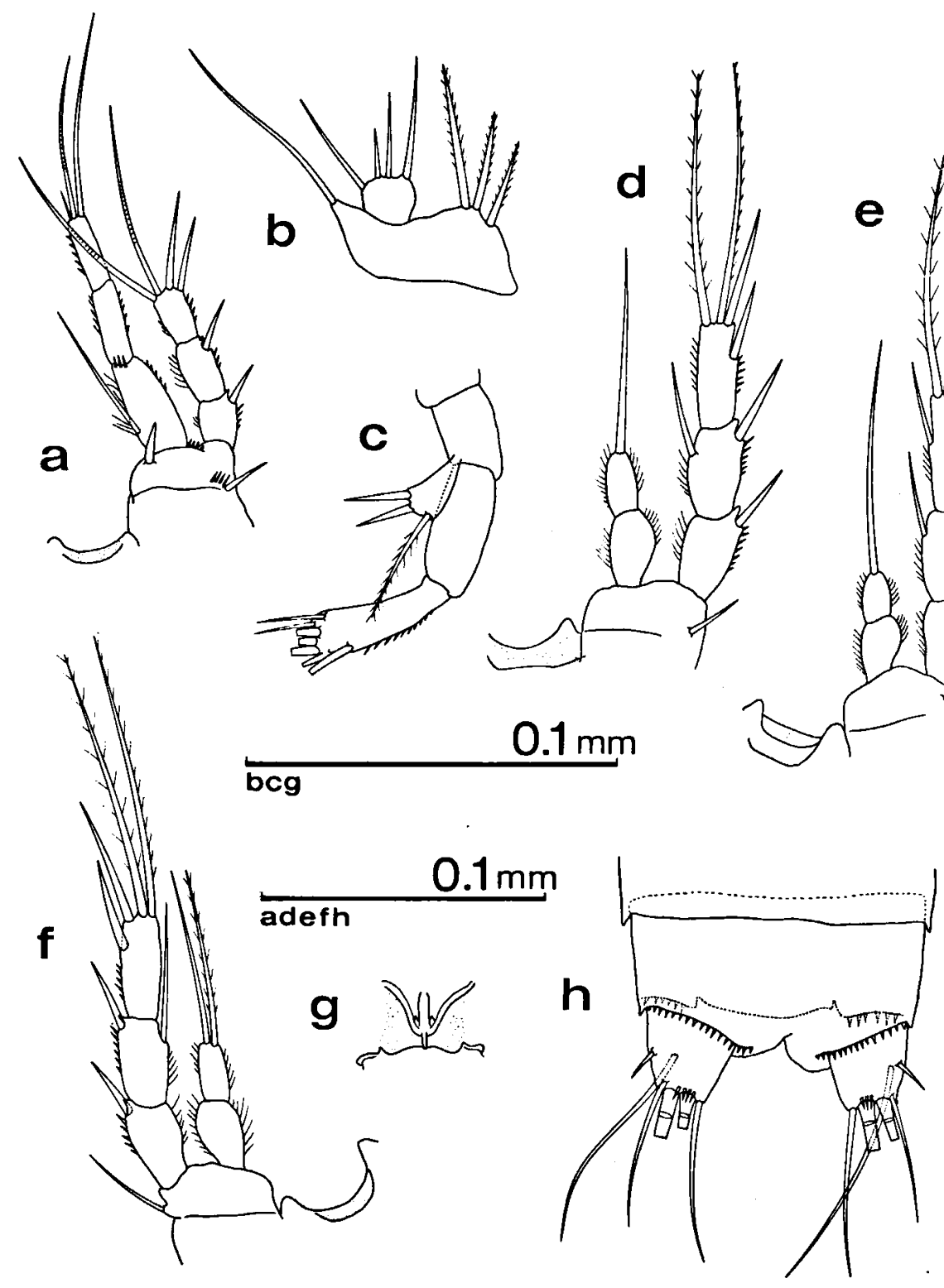

Fig. 1. Nitocrella petkovskii n. sp., + . a, $P_{1} ; b, P_{5} ; c$, antenna, exopod; d, $P_{2} ; e, P_{4} ; f, P_{3} ; g$, genital field; h, furcal rami and anal operculum, ventral view.

$\mathrm{P}_{3}$ 3-segmented; article 1 with 1 outer spine, article 2 with 1 outer spine and 1 long inner seta, article 3 with 2 subapical spines and 2 long apical setae; exopod of $\mathrm{P}_{4}$, articles 1 and 2 as those of $\mathrm{P}_{2}$ and $P_{3}$, article 3 armed with 5 setae or spines ( 3 apically implanted, 1 on the inner and 1 on the outer margin).
Setal formula $P_{1}-P_{4}$ as follows:

\begin{tabular}{|c|c|c|}
\hline & exopod & endopod \\
\hline $\mathbf{P}_{1}$ & 00022 & $\begin{array}{lll}10 & 120\end{array}$ \\
\hline$P_{2}$ & 01022 & -0010 \\
\hline$P_{3}$ & 01022 & -0020 \\
\hline D & $\begin{array}{lll}0 & 1 & 122\end{array}$ & -0010 \\
\hline
\end{tabular}

$P_{5}$ : basiendopod with 3 inner barbed spines; 
exopod about as long as wide, bearing 4 setae of different sizes.

Furcal rami conical, slightly longer than wide; outer margin with a small seta; dorsal surface with a long seta, about 3.5 times longer than each furcal ramus; apically there are 4 setae: the outer is the shorter (about twice the length of the furcal ramus), the inner is about 1.3 times longer than the outer one, the mediodistal ones are the longest and of different size (the inner about 1.85 times as long as the outer one).

Anal operculum with naked distal margin and 6 - 7 small spinules on each side.

Male: Construction and armature of the thoracic and abdominal appendages, as well as its other characteristics, with the exception of the antennulae, are comparable to those of the female.

Etymology. - I take great pleasure in naming this species after Prof. T. K. Petkovski, in recognition of his valuable contributions to the systematics of the genus Nitocrella.

A f f in it i es. - Petkovski (1976) recently reviewed the systematics of the genus Nitocrella Chappuis s.l. In that review three species groups within Nitocrella s. str. were recognized, viz. the vasconica group (characterized by 6 spines or setae on article 3 of the $\mathrm{P}_{4}$ exopod), the chappuisi group (characterized by 5 spines or setae on the distal article of the $\mathrm{P}_{4}$ exopod), and the birta group (with 3 to 4 spines or setae on that article).

According to this revision, Nitocrella petkovskii n. sp. fits well in the chappuisi group, since the 3 rd article of the $\mathrm{P}_{4}$ exopod is armed with 3 spines and 2 setae.

Among the species of this group, $N$. petkovskii n. sp. is close to $N$. neutra Kiefer and $N$. bypogaea Shen \& Tai. Particularly to the former the new species resembles by the armature of the basiendopod of $P_{5}$ and the number of setae on the distal article of the endopod of $P_{2}$ and $P_{4}$. To the latter species, it resembles by the armature of the distal article of the endopods of $P_{2}$ to $P_{4}$.

$N$. petkovskii n. sp. differs from the above species as follows:

- from N. neutra in having 4 (instead of 5) elements (setae or spines) on article 3 of the $P_{1}$ exo- pod, in having longer setae on article 3 of the exopods of $P_{2}$ to $P_{4}$, in the shorter exopod of $P_{5}$, and in the unarmed anal operculum (versus armed with 6-8 small spines);

- from $N$. bypogaea by the quite different shape and length of the furcal rami, by the presence of 3 spines on the inner margin of the basiendopod of $P_{5}$ (versus a vestigial basiendopod with 1 outer spine only), by the shape of the exopod of $P_{5}$, and by the long inner seta on article 1 of the $\mathrm{P}_{1}$ endopod (versus an unarmed article).

\section{Nitocrella paceae n. sp. Fig. 2}

Material. One $q$ and one juv. (copepodid IV), freshwater well at Shar-e-Kord, (former) Palavi road, Isfahan, $2,200 \mathrm{~m}$ above sea-level (water level at $5.2 \mathrm{~m}$, water depth $2.2 \mathrm{~m}$; temperature $17.0^{\circ} \mathrm{C} ; \mathrm{pH} 7.5$; bottom sediment composed of small vegetable and sandstone detritus); May 21, 1978; coll. Pace \& Rahim. Accompanying fauna: Diacyclops bisetosus (Rehberg) and Eucyclops serrulatus (Fischer) (both cyclopid copepods), Candoninae (Ostracoda), Nais elinguis (Müller) and Peloscolex velutinus (Grube) (both Oligochaeta), and water mites.

One $q$ and two juv. (copepodid IV) from sample IR. 34 (see for details about this locality under Nitocrella petkovskii).

Types. One $\&$ (holotype), completely dissected and mounted in Faure's medium on microscope slides, deposited in the Zoölogisch Museum, Amsterdam; other materials (paratypes) in the Zoological Institute of the University of L'Aquila (author's collections).

Description. - Female: Body slender and elongate; unpigmented and blind; length between 0.38 and $0.41 \mathrm{~mm}$, including furcal rami but excluding furcal setae, antennae and antennulae. Antennula 8-segmented, aesthete on the 4th article slightly longer than the following articles together. Antenna, exopod 1-segmented, subtriangular, and armed with 3 apical setae, the inner clearly plumose. Mouthparts without particular characteristics. Distal margin of the thoracic segments without hyaline lamellae or spines.

$\mathrm{P}_{1}$ : endopod and exopod 3-segmented; endopod, article 1 short (reaching about the middle of the 2nd exopod article) and with a long inner seta, article 2 without setae or spines, article 3 with 2 long setae; exopod shorter than endopod, slightly overreaching the 2nd article of the endopod; articles 1 and 2 each with a spine on the outer sub- 

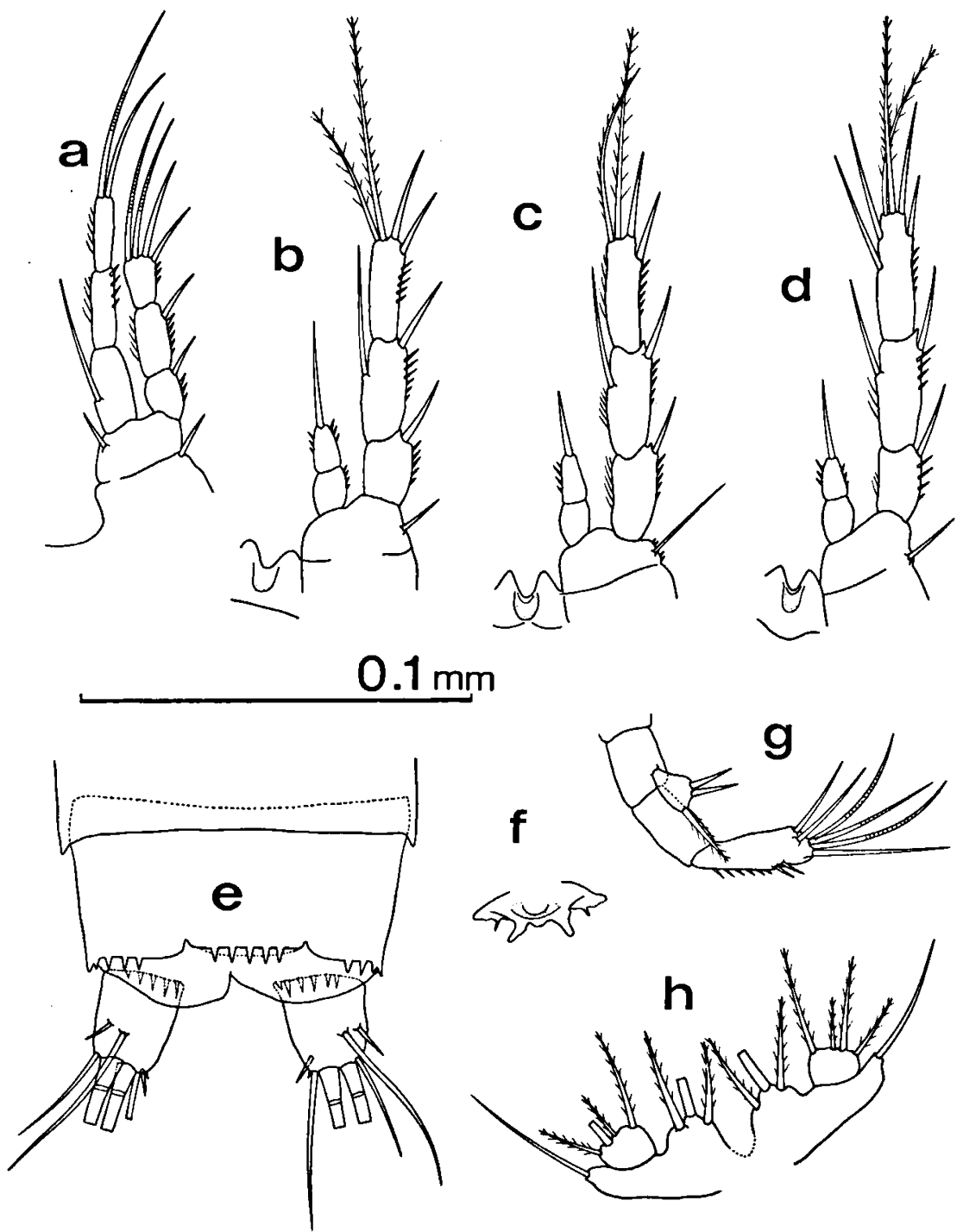

Fig. 2. Nitocrella paceae n. sp., $\uparrow$. a, $P_{5} ; b, c, d, P_{2} \cdot P_{4} ;$ e, furcal rami and anal operculum, dorsal view; $f$, genital field; $\mathrm{g}$, antenna, exopod; $h, P_{5}$.

distal margin, article 3 with 2 apical setae and 2 subapical setiform spines.

$\mathrm{P}_{2}-\mathrm{P}_{4}$ : endopod 2-segmented, clearly overreaching the first article of the exopod; articles 1 and 2 about of the same length, article 2 with a short apical seta. Exopods of $P_{2}$ and $P_{3}$ very similar, 3segmented; article 1 with a subdistal outer spine, article 2 with an outer subdistal spine and a long inner seta; exopod of $\mathrm{P}_{4}$ 3-segmented, articles 1 and 2 as in $P_{2}$ and $P_{3}$, article 3 armed with 6 spines and setae ( 2 inner +2 apical setae, and 2 outer, subdistal spines).
Coxal plates of $\mathrm{P}_{2}-\mathrm{P}_{4}$ with markedly prominent lobes.

Setal formula of $\mathrm{P}_{1}-\mathrm{P}_{4}$ as follows:

\begin{tabular}{|c|c|c|}
\hline & exopod & endopod \\
\hline & 00022 & 10020 \\
\hline & 01022 & -0010 \\
\hline & 01022 & -0010 \\
\hline & 01222 & -0010 \\
\hline
\end{tabular}

$P_{5}$ : basiendopod with 3 stout setae (one damaged in all specimens) on the inner margin and 1 slender seta on the distal corner; exopod slightly wider than long and armed with 4 plumose setae. 
Anal operculum with slightly convex medial margin, armed with 5- 6 spines; lateral margins each with $3-4$ spines.

Furcal rami subparallel, slightly longer than wide $(\mathrm{L} / \mathrm{l}=1.22-1.24)$, armed with a short lateral seta, a long dorsal seta (about twice longer than each ramus) and 4 distal setae, the inner longer than the outer and about as long as the dorsal one; medial setae both damaged; a small setula is implanted on the inner subdistal margin of each ramus.

Male: Unknown.

Ety mology. - This species is named after Miss Raffaella Pace who collected it.

A f $\mathrm{f}$ in ities. - Nitocrella paceae n. sp. quite clearly belongs to the vasconica group of species within Nitocrella s. str., as described by Petkovski (1976). Within this group, N. paceae n. sp. is closely related to $N$. vasconica Chappuis, mainly through the armature of the basiendopod of $P_{5}$. From this species, as well as from the others in the same group, $N$. paceae is most readily distinguished by numerous characteristics such as the construction and armature of $\mathrm{P}_{1}$, the armature of the anal operculum, the morphology of the $P_{5}$ exopod, the length and armature of the furcal rami, etc.

\section{LITERATURE}

Chappuis, P. A., 1937. Subterrane Harpacticoiden aus NordSpanien. Bul. Soc. Sti. Cluj., 8: 556-571.

KIEFER, F., 1933. Neue süsswasser Copepoden aus Jugoslawien. Zool. Anz., 101: 309-318.

PEsce, G. L., in press. Biocenosi sotterranee freatiche dell'Iran nord-occidentale. Riv. Idrobiol.

PETKovskI, T. K., 1976. Drei neue Nitocrella-Arten von Cuba, zugleich eine Revision des Genus Nitocrella Chappuis (s. restr.) (Crustacea, Copepoda, Ameiridae). Acta Mus. Mac. Sci. nat., 15 (1): 1-26.

Shen, C. J. \& A. Y. TAI, 1973. Preliminary analysis of the harpacticoid Copepoda-fauna of China and description of some new species. Acta zool. sin., 19 (4): 365-384. 